\title{
Winnicott en la perspectiva relacional e intersubjetiva actual, acompañados por las poesías de Joan Manuel Serrat ${ }^{1}$
}

\author{
Francesc Sainz i Bermejo ${ }^{2}$ \\ Institut Català D. Winnicott (Barcelona), IPR, SEP
}

Winnicott además de psicoanalista era pediatra y por lo tanto conocedor de las llamadas competencias del bebé, pero no dudó ni un segundo cuando pronunció su conocida "boutade" en el año 1940, ante la sociedad psicoanalítica. El Dr. Winnicott experto en bebés afirma que "No existe tal cosa que podamos llamar bebé", dicho en breve, "El bebé no existe", por muchas competencias que tenga, necesita de un otro para estructurar su identidad como persona. Si el recién nacido no existe, tampoco existe la mamá que le cuida, de igual manera que el analista y el paciente no existen de forma aislada. Las relaciones humanas en tanto se convierten en vínculos afectivos, se construyen entre sus participantes que mantienen una interdependencia necesaria.

Los autores intersubjetivos sostienen que esta frase winnicottiana aparentemente obvia se convierte en el pilar sobre el que se edifica el psicoanálisis, especialmente el que hoy llamamos, psicoanálisis relacional.

El bebé se siente bebé cuando se mira en los ojos de su mamá y la mamá se siente mamá cuando se ve reflejada en los ojos de su niño. Soy el que soy a los ojos del otro. Para construir su identidad, el humano tiene la necesidad de pertenecer a alguien que le pertenece. Si soy de alguien que me cuida y me deja crecer, podré llegar a ser yo mismo.

Para los más clásicos, diré que el psicoanálisis siempre ha sido relacional, desde Freud, por lo que no es nuevo. Sin embargo, se produce una perspectiva algo diferente cuando el acento de la melodía está puesto en la relacionalidad. Se ve reflejado en la manera de entender la salud, la psicopatología y la forma de intervenir psicoterapéuticamente. ${ }^{1}$

La perspectiva relacional en el psicoanálisis no solo es tener en cuenta la relacionalidad del sujeto o dar credibilidad a la realidad externa, sino que compromete al propio analista, que no

\footnotetext{
${ }^{1}$ Trabajo que fue posteriormente presentado en el Panel "Winnicott y el pensamiento contemporáneo" en el XVII Encuentro Latino-Americano sobre el Pensamiento de Winnicott, Buenos Aires, 6 al 9 de Diciembre de 2018.

${ }^{2}$ Francesc Sáinz Bermejo es Psicoanalista de la SEP/IPA. Miembro titular de IPR. Presidente del Institut Català D.W. Winnicott Barcelona. Autor de la obra: Winnicott y la perspectiva relacional en psicoanálisis (Barcelona: Herder, 2017) y de otros trabajos sobre el pensamiento e influencia de Winnicott. Dirección de contacto: francescsainz@gmail.com
} 
se ofrece como mero interpretador del mundo interno del paciente o de la transferencia, sino que se implica como elemento activo y sistémico de la relación analítica.

Entendemos que el funcionamiento mental conlleva un interjuego de proyecciones e introyecciones, que las realidades del paciente son inescrutables, pero si el terapeuta trabaja junto con su paciente, al lado de él, se podrán deshilar los elementos subjetivos y objetivos de su historia, dentro de lo que esto es posible. Las realidades pueden hacer mucho bien, pero pueden causar un gran daño, el terapeuta debe ayudar a que el paciente conozca las dinámicas relaciones en las que se ha visto sumergido e implicado desde el inicio de su vida.

Freud dejó una obra completa en la que urdió las bases para el psicoanálisis, como Galeno lo hizo con la medicina. Los continuadores de su obra pudieron recoger los frutos y desarrollar teorías nuevas, paradigmas, líneas de pensamiento. Unos cuantos fueron los autores que crearon escuelas que llevaban sus nombres, escuelas de autor: Lacan, Jung, Klein, entre otros; de manera que identificamos teoría con autor. Otros psicoanalistas trabajaron en solitario, tal vez no tenían la capacidad o la necesidad de crear escuela nominal y quizás por ello, gozaron de mayor libertad de pensamiento y de movimiento. Destacamos a Ferenczi que pidió a Freud que no desestimara la teoría traumática. Los miembros del "Independent group británico" en los años siguientes a las controversias, fueron muy creativos y la mayoría de ellos, como había hecho Ferenczi, tuvieron una alta implicación con problemáticas psicosociales de la época, con niños abusados, maltratados, abandonados, lo que considero que influyó directamente en sus formulaciones tóricas y clínicas. Fue el caso del escocés Fairbairn y del imprescindible Bowlby que auspició sendas filmaciones reales sobre los efectos dañinos de la separación del niño con su entorno afectivo. Balint trabajó esencialmente con el sufrimiento que los médicos tenían con sus pacientes difíciles y Winnicott tuvo contacto directo con chicos separados de sus padres por la guerra y con tendencias delincuenciales.

Es obvio que el paciente necesita repetir el dolor causado en su pasado en la transferencia, pero creo que el psicoanalista no debe interpretarlo necesariamente, sino recogerlo, asumiendo las propias fallas. El analista es receptor y a la vez se debe responsabilizar como emisor de algunos fallos que el paciente pudo vivir, ahora entendidos como algo presente, real, vivencial y abordable.

La transferencia y la contratransferencia no son fenómenos unidireccionales, sino al contrario pertenecen a la transicionalidad creada entre paciente y terapeuta. En niveles distintos de implicación. El analista es constructor junto con su paciente de los fenómenos transferenciales y contratransferenciales.

Lo viejo se funde con lo nuevo de la experiencia terapéutica. El analista se ofrece al paciente como un semejante a él, cercano, poco interpretador, propiciando un holding consistente y 
flexible que permita el desarrollo de una experiencia confiada y auténtica. Al mismo tiempo el analista debe ser falible, capaz de fallar al paciente y reconocérselo, dispuesto a ser, por lo tanto, suficiente e insuficientemente bueno.

Winnicott lo entendió así por eso no desaprovechó la ocasión de decírselo a la ex - paciente que le pidió la ampliación de una foto que vio en un libro de su querido analista.

«La paciente creía que no hacía más que adquirir el retrato de ese hombre que tanto había hecho por ella (y así es). Pero necesitaba que se le dijera que mi rostro surcado de arrugas tenía ciertos rasgos que para ella se vinculan con la rigidez de los de su madre y su nodriza» (Winnicott, 1971a, p. 153).

El objetivo terapéutico de Winnicott con sus pacientes era el de promover una experiencia compartida y co-construida entre ambos en la que la persona pudiera sentirse real. Les ayudaba a sentir para poder pensar y en algunos casos, comprender. La interpretación psicoanalítica no era el instrumento primordial para Winnicott. "A menudo interpreto para que el paciente vea los límites de mi comprensión". Si lo era, la experiencia emocional y relacional entre ambos, lejos de las idealizaciones personales y del propio psicoanálisis como tal.

Debemos ser cautos con las interpretaciones que revelan el supuesto material inconsciente que subyace en los síntomas; es mucho más importante, desde mi punto de vista, ayudar a conocer los caminos trazados por la disociación, ayudar a establecer nexos entre emociones, sentimientos y las experiencias vitales.

La conexión entre la emoción ligada a lo somático, el cuerpo y las experiencias relacionales (Winnicott, 1949), necesitan de una mente tranquila que las recoja.

El niño cuidado en sus necesidades corpóreas, de forma sensible y continuada, puede ubicar sus emociones que están arraigadas a lo somático. Su mamá le presta su mente, incluso su falso self, para protegerlo. La mente calmada, tranquila y confiada ocupa poco espacio. Es cuando se siente en peligro que aparece la tendencia a hipertrofiarse o a inhibirse. Si predomina la confianza, si se le da tiempo y espacio a la criatura, la mente irá haciendo su aparición y se ocupará de recoger la experiencia vivida para hacerla propia.

La mentalización hoy en boga, no se consigue a través de la interpretación, sino a través de las vivencias que permiten conectar estos elementos descritos y una mente capaz de recogerlos y reflexionarlos. 
He llegado a a la conclusión de que en el proceso del insight la mente y el yo no intervienen de forma activa, deben ocupar poco lugar, dejarse ir con autenticidad y confianza, intervienen para recoger la experiencia, para sentirla y pensarla y ubicarla. Mucha mente impide la mentalización, dije en una ocasión, siguiendo el excelente trabajo de 1949, "La mente y su relación con el psique-soma.

Así lo expresaba una paciente: "El otro día me pasó lo mismo de siempre, pero me sentí distinta, reaccioné diferente a lo habitual, no se bien por qué, pero sé que hay algo nuevo en mi". Pues vamos a verlo juntos, pedimos ayuda a la mente, al yo consciente para que nos ayude comprender que es lo que ha cambiado.

La genialidad de Freud llevó a considerar que el paciente debía permitirse la libertad asociativa de sus contenidos mentales, creo que lo que proponía era que el paciente se permitiera la disociación libre, él mantendría la atención flotante. Winnicott sabía que la libertad consistía en dejar ser lo que cada uno puede ser, se permitía la no-integración de pensamientos y le facilitaba al paciente que pudiera hacerlo. El mismo proceso que sigue la experiencia creativa, permitirse incluso el derrumbe con la esperanza de que alguien sostenga y entienda lo que sucede.

Winnicott era sensible al sufrimiento humano y especialmente al de los niños, la realidad externa es una buena aliada de la salud mental, pero también puede ser la causante de infringir dolor, según sean las capacidades del niño y sobretodo la respuesta del entorno, el dolor excesivo puede convertirse en plataforma sobre la que se asienta la psicopatología (Talarn, Sáinz y Rigat, 2013). "A fuerza de desventuras, su alma es profunda y oscura "canta Serrat en Mediterráneo. Se refiere al mar mediterráneo, pero lo podemos referir también a los niños, las desventuras continuadas, los traumas acontecidos o aquellos que nunca sucedieron, golpean la salud mental del pequeño. Su alma, sus mentes y sus cerebros quedan comprometidos emocionalmente. Cómo podemos desoscurecer y desprofundizar ese daño causado, la respuesta es que es, sobre todo, ofreciendo una nueva relación afectiva, un nuevo vínculo, aunque no siempre se consiga. Sabemos con Bowlby, Winnicott algo que nos canta Serrat, que llevamos la luz y el olor de las experiencias por dondequiera y con quienquiera que vayamos y nos dice que eso tal vez es "porque mi niñez sigue jugando en tu playa y escondido tras las cañas duerme mi primer amor" (primer amor, primeros vínculos afectivos).

Winnicott cuando sentía el dolor de sus pacientes, en algunas ocasiones lo compartía con ellos, al mismo tiempo que se hacía cargo de sus propias limitaciones para la empatía. Es como decir siento con usted, pero yo no soy usted, mi percepción puede estar sesgada y equivocada como les pudo pasar a sus padres. Pero ahora lo podemos reconocerlo, lo podemos hablar. 
Dijo a un paciente: "El loco soy yo que veo un hombre estirado en mi diván, pero escucho a una mujer". Su madre nunca pudo reconocerle que estaba loca y que era capaz de volverle loco a él. También le dijo a Margaret Little, como ustedes saben. "Necesito que sepa en este momento, que yo odio a su madre".

Estos ejemplos convierten a nuestro querido autor en un pionero indiscutible del psicoanálisis relacional. Winnicott sabe que no es un receptáculo en una relación desigual, sino que está implicado con su subjetividad, para comprender la subjetividad del paciente; ambos comparten una mutualidad psíquica, un espacio transicional e intersubjetivo, aunque mantengan, y así lo cree Winnicott, una necesaria relación asimétrica. La experiencia terapéutica es transformadora, de alguna manera, para los dos integrantes que la componen.

Cierta neutralidad por parte del analista es necesaria, pero no podemos ni debemos ser neutrales, más vale reconocerlo. Lo menos neutral que existe es considerarse neutral como hacía Meltzer cuando era joven que vestía tres trajes del mismo color para reducir los estímulos ante el paciente.

Winnicott siempre respetó la pulsionalidad, pero le gustaba más hablar de constitucionalidad. A mi me pasa igual, me interesa más la biología que la pulsión.

En mi reciente libro (Sáinz, 2017) digo que es obvio que el ser humano nace con una pulsión fundamental: la búsqueda de un otro para relacionarse y construir su identidad, esta es la base de la pulsión de vida; también viene dotado de la capacidad de defenderse, de agredir y de odiar, pero vale la pena tener en cuenta lo que dice Winnicott:

Sí es verdad que el niño tiene una enorme capacidad para la destrucción, pero también la tiene para proteger lo que ama de su propia destrucción. (1939, p. 108).

La agresión tiene dos significados: por un lado, es directa o indirectamente una reacción ante la frustración; por el otro, es una de las dos fuentes principales de energía que posee el individuo.

(1964a, p. 114)

La pulsionalidad debe ser ubicada en la experiencia relacional, en la manera que tienen los cuidadores de recibirla, interpretarla y devolverla.

Las pulsiones y las tendencias edípicas no se pueden estudiar de forma aislada, siempre hay un otro con características propias que recibe y emite al mismo tiempo contenidos mentales, cognitivos y emocionales. las identificaciones siempre son cruzadas.

Para verme necesito la mirada del otro, En realidad miro para ser mirado y reconocido (Winnicott, 1968). Pero la figura materna no es un espejo bidimensional que únicamente 
devuelve imágenes. Es un espejo que se deja mirar dentro de si mismo, el pequeño mira a su mamá y puede ver que dentro de ella hay contenidos, estados de ánimo, sentimientos. Propongo la idea de que probablemente el niño descubre que su figura adulta cuidadora tiene un interior y eso le lleva poco a poco a reconocer que él mismo también lo tiene.

Fomentar la experiencia transicional y estimular la capacidad de jugar, es el instrumento terapéutico más valioso que tenemos, y a la vez es el objetivo terapéutico. Tratamos de ayudar al paciente con creatividad para que el pueda llegar a ser creativo, pueda jugar y atreverse a vivir su propia vida en primera persona.

Los analistas tenemos un método de trabajo que perdura con el cambio de los tiempos, es natural porque los sentimientos humanos han modificado su forma de expresión, pero no su esencia; Sócrates, los literatos de todos los tiempos, hoy día el cine, nos ayudan a conocerlos y a estudiarlos, también los poetas, y los cantautores. En todo el mundo, y especialmente en latino-América hay un extraordinario patrimonio de sabidurías compartidas a través de letras y músicas de tantos de ellos.

Escribí sobre Serrat para divulgar algunas ideas psicoanalíticas. Me pasa con él como con Winnicott, creo que muchos de ustedes compartirán conmigo este mismo pensamiento, que nunca dejan de sorprenderme y que ambos tratan la vida y lo que acontece sin idealizaciones, en la cotidianidad, "Tal com raja"2.

Serrat acepta el desamor, el dolor, no lo elude, lo vive, lo siente y trata de comprenderlo, no de resolverlo. Fíjense en "La mujer que yo quiero" que tiene muchos defectos y que es más importante que el pan de la tierra. En "De mica en mica" donde conoció a la chica poco a poco, se fueron queriendo y un día le dejó y se tuvo que desacostumbrar a su compañía y lo hizo psicoanalíticamente, a fuego lento. O en "A ese pájaro dorado" que se le da bien la excepcionalidad, pero no le sienta bien la ropa de diario. Les propongo que pensemos juntos aquí y ahora algunas canciones más de este cantautor catalán que me consta es tan querido por todos ustedes. (Mientras cenamos, tal vez)

Winnicott afirmó en una ocasión "Que si hay algo de verdad en lo que les digo, los poetas lo habrán dicho antes", me permito devolverle que "Si hay algo de verdad en lo que los poetas y los artistas nos enseñan, Winnicott lo habrá tenido en cuenta", no les quepa la menor duda.

\section{REFERENCIAS}

Los textos principales del propio autor en los que se basa este trabajo son: 
Sáinz, F. (2014). Sentir y pensar con Serrat. Reflexiones de un psicoanalista de hoy a partir de la obra del poeta y músico: Lleida: Milenio

Sáinz, F. (2017). Winnicott y la perspectiva relacional en el psicoanálisis. Barcelona: Herder-Fundació Vidal i Barraquer.

Sáinz, F. (2018). Winnicott's contributions for the Relational Perspective in Psychoanalysis. En Ávila, A. (Ed), Relational Horizons: Mediterranean voices bring passion and reason to relational psychoanalysis. Astoria, NY, U.S.A.: International Psychoanalytic Books.

\section{Bibliografia citada en este trabajo:}

Winnicott, D. W (1939), La agresión en relación con el desarrollo emocional. En Escritos de pediatría y psicoanálisis, Barcelona: Paidós, 1998.

Winnicott, D.W (1949). La mente y su relación con el psique-soma. En Escritos de pediatría y psicoanálisis, Barcelona: Paidós, 1998, pp. 325-340.

Winnicott, D.W. (1964). El niño, la familia y el mundo externo. Barcelona: Paidos 2009.

Winnicott, D.W. (1967). Papel de espejo de la madre y la familia en el desarrollo del individuo. En: Realidad y Juego. Barcelona: Gedisa, 2009, pp. 147-155.

Winnicott, D. W. (1971). Realidad y juego, Barcelona: Gedisa, 2009.

Talarn, A.; Sáinz, F. y Rigat, A. (2013). Relaciones, vivencias y psicopatología. Las bases relacionales del sufrimiento mental excesivo. Barcelona: Herder.

Original recibido con fecha: 31/8/2018 Revisado: 25/10/2018 Aceptado: 30/10/2018

\section{Cita bibliográfica / Reference citation:}

Sainz Bermejo, F. (2018). Winnicott en la perspectiva relacional e intersubjetiva actual, acompañados por las poesías de Joan Manuel Serrat. Clínica e Investigación Relacional, 12 (3): 568-574. [ISSN 1988-2939] [Recuperado de www.ceir.info ] DOI: 10.21110/19882939.2018.120310

NOTAS:

${ }^{1}$ El Psicoanálisis Relacional se da a conocer a partir de finales de los go en EEUU, Italia, Canadá... En España destaca la labor de Alejandro Ávila en Madrid con el que estamos en contacto Joan Coderch y algunos de nosotros de Barcelona.

${ }^{2}$ Expresión catalana que significa: Tal como surge, tal como emana. 